\title{
Матричный синтез монодисперсных сферических нанокомпозитных частиц $\mathrm{SiO}_{2} / \mathrm{GaN}: \mathrm{Eu}^{3+}$
}

\author{
(C) Е.Ю. Стовпяга ${ }^{1}$, Д.А. Еуров ${ }^{1}$, Д.А. Курдюков ${ }^{1}$, А.Н. Смирнов ${ }^{1}$, \\ M.A. Яговкина ${ }^{1}$, D.R. Yakovlev², В.Г. Голубев ${ }^{1}$ \\ ${ }^{1}$ Физико-технический институт им. А.Ф. Иоффре Российской академии наук, \\ 194021 Санкт-Петербург, Россия \\ ${ }^{2}$ Experimentelle Physik 2, Technische Universität Dortmund, \\ D-44227 Dortmund, Germany \\ E-mail: kattrof@gvg.ioffe.ru
}

(Получена 12 февраля 2018 г. Принята к печати 19 февраля 2018 г.)

\begin{abstract}
Матричным методом получен нанокомпозит, представляющий собой монодисперсные сферические мезопористые частицы кремнезема $\left(\mathrm{mSiO}_{2}\right)$, заполненные $\mathrm{GaN}: \mathrm{Eu}^{3+}$. Метод основан на однократной пропитке пор частиц $\mathrm{mSiO}_{2}$ расплавом кристаллогидрата нитратов галлия и европия $(0.22 \mathrm{Mac} \%)$, с последующим терморазложением и обработкой в атмосфере аммиака. Показано, что нанокомпозитные частицы содержат гексагональный $\mathrm{GaN}: \mathrm{Eu}^{3+}$, являются монодисперсными, имеют сферическую форму и не слипаются друг с другом. В спектрах фотолюминесценции нанокомпозитных частиц $\mathrm{mSiO}_{2} / \mathrm{GaN}^{2} \mathrm{Eu}^{3+}$ наблюдается группа линий, характерных для внутрицентровых переходов в ионах $\mathrm{Eu}^{3+}$.
\end{abstract}

DOI: 10.21883/FTP.2018.09.46147.8843

\section{1. Введение}

Неослабевающий интерес к разработке методов синтеза и исследованию различного типа нанокомпозитов обусловлен широким спектром их возможных практических применений. В частности, наномпозиты могут применяться как конструкционные материалы с улучшенными механическими характеристиками, сенсоры различных типов и назначений, топливные элементы, катализаторы [1-6]. Одним из технологических подходов к созданию нанокомпозитов является внедрение химическими или физическими методами наноразмерных объектов (наночастиц, нанокристаллитов, нанонитей) внутрь мезо- и макропористых полимерных или неорганических матриц [1-6]. Использование пористых матриц различной топологии с контролируемым размером пор позволяет получать нанообъекты с заданными размерами, структурой и физико-химическими свойствами. Так, например, для синтеза нанокомпозитов широко применяются пористые кремнеземные матрицы, в которых размер пор управляемой формы контролируемо варьируется в диапазоне от единиц до сотен нанометров $[1,4,5]$.

Получение нанокомпозитов на основе кремнеземных $\left(\mathrm{SiO}_{2}\right)$ матриц и нитрида галлия $(\mathrm{GaN})$, являющегося ключевым материалом современной оптоэлектроники, представляет как фундаментальный, так и практический интерес. Наноразмерный нитрид галлия, легированный ионами редкоземельных элементов, может быть использован, например, в медицине и для производства высокоэффективных детекторов радиации [7-10]. Ранее была разработана методика синтеза нанокомпозита $\mathrm{SiO}_{2} / \mathrm{GaN}$ [11-13], в котором в качестве кремнеземной матрицы использовался синтетический опал, имеющий макропоры размером 50-100 нм. Образец опала пропитывался раствором соли галлия, смачивающим поверх- ность пор матрицы, вследствие капиллярного эффекта. Затем при термообработке соль в порах матрицы разлагалась до оксида, и проводился гетерогенный синтез $\mathrm{GaN}$ из $\mathrm{Ga}_{2} \mathrm{O}_{3}$ посредством отжига образца в атмосфере аммиака.

Проведение гетерогенных реакций в порах нанометрового размера осложнено тем, что массоперенос газообразных реагентов и продуктов протекает медленно, посредством поверхностной диффузии [14,15]. Малая скорость удаления газообразных продуктов из пор не только значительно уменьшает скорость протекания реакций, но и смещает химическое равновесие по принципу ЛеШателье в сторону исходных веществ, препятствуя синтезу целевого вещества. При уменьшении размера пор в 10 раз скорость массопереноса падает в $\sim 100$ раз [16]. Поэтому осуществление гетерогенного синтеза $\mathrm{GaN}$ в мезопористых матрицах с размерами пор в единицы нанометров сложнее, чем в порах опала. Еще более трудной задачей является синтез $\mathrm{GaN}$ в порах матрицы, представляющей собой монодисперсные сферические мезопористные частицы кремнезема (МСМЧК), что перспективно для применений, например, в медицине. Проводя синтез в порах МСМЧК, необходимо обеспечивать селективное заполнение пор частиц без осаждения наполнителя на их внешнюю поверхность, без коалесценции частиц и без существенного изменения их размеров и формы.

В настоящей работе в термодинамически равновесных условиях реализован гетерогенный синтез нанокристаллитов нитрида галлия, легированного ионами европия $\left(\mathrm{GaN}: \mathrm{Eu}^{3+}\right)$, в трехнанометровых цилиндрических поpax МСМЧК без осаждения массивного (bulk) вещества на поверхность частиц. Селективное заполнение мезопор обеспечивалось за счет значительного отличия капиллярного (лапласова) давления расплава кристал- 
логидрата нитрата галлия в мезопорах и пространстве между частицами. Проведена морфологическая, структурная и оптическая характеризация синтезированных нанокомпозитных частиц методами атомно-силовой микроскопии (АСМ), динамического светорассеяния (ДСР), рентгеновской дифракции и рамановского рассеяния. Показано, что частицы $\mathrm{mSiO}_{2} / \mathrm{GaN}: \mathrm{Eu}^{3+}$ сохраняют сферическую форму и монодисперсность.

\section{2. Методика эксперимента}

Монодисперсные сферические мезопористые частицы кремнезема диаметром 210 нм синтезированы путем гидролиза тетраэтоксисилана в этаноло-водно-аммиачной среде в присутствии структурообразующего вещества цетилтриметиламмоний бромида в мольном соотношении реагентов $1: 250: 45: 400: 0.25$ соответственно. Для удаления органических веществ синтезированные частицы были отожжены на воздухе при температуре $800 \mathrm{~K}$. Среднеквадратичное отклонение диаметров частиц составило менее 6\%, диаметр мезопор

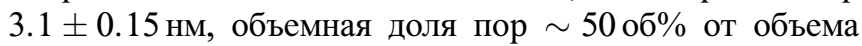
частиц, удельная поверхность $720 \mathrm{M}^{2} /$ г. Подробно методика синтеза частиц описана в работах $[17,18]$.

Синтезированные МСМЧК заполняли расплавом смеси кристаллогидратов $\mathrm{Ga}\left(\mathrm{NO}_{3}\right)_{3} \cdot 8 \mathrm{H}_{2} \mathrm{O}$ и $\mathrm{Eu}\left(\mathrm{NO}_{3}\right)_{3} \cdot 6 \mathrm{H}_{2} \mathrm{O}(0.22$ мас\%). МСМЧК выдерживались в расплаве в течение 3 ч. Затем образцы высушивали при $400 \mathrm{~K}$, нагревали с шагом $1{ }^{\circ} \mathrm{C} /$ мин до $T=800 \mathrm{~K}$ и отжигали в течение 3 ч для разложения нитратов до оксидов $\mathrm{Ga}_{2} \mathrm{O}_{3}$ и $\mathrm{Eu}_{2} \mathrm{O}_{3}$. Степень заполнения пор МСМЧК оксидами определялась из значения плотности частиц, рассчитываемой по уравнению Стокса. Необходимое для расчета значение скорости седиментации диспергированных в воде частиц измерялось экспериментально.

Нитрид галлия, легированный ионами европия, синтезировали путем отжига МСМЧК, заполненных оксидами галлия и европия, в атмосфере аммиака при температуре $1300 \mathrm{~K}$ в течение 20 ч.

Микроскопические исследования выполнялись с помощью атомно-силового микроскопа NT-MDT SMENA в полуконтактном режиме. Распределение МСМЧК, заполненных $\mathrm{GaN}: \mathrm{Eu}^{3+}$, по размерам регистрировали методом динамического светорассеяния на приборе Malvern Zetasizer Nano при температуре 298 K. Рacчет распределения гидродинамических диаметров частиц осуществлялся автоматически на основе анализа корреляционной функции флуктуаций интенсивности рассеянного света с помощью алгоритма мультимодального узкого распределения, входящего в состав программного обеспечения анализатора.

Фазовый состав нанокомпозитов определялся рентгенодифракционным методом на установке D2Phaser, Bruker, Германия (CuK $K_{\alpha}$-излучение). Рамановские спектры и спектры фотолюминесценции (ФЛ) измерялись при комнатной температуре на спектрометре Horiba
Jobin Yvon T64000, с использованием в качестве источника излучения второй гармоники $\mathrm{Nd}$ : YAG-лазера $(\lambda=532 \mathrm{нм})$, плотность возбуждения на поверхности образца не превышала $P=2$ кВт $/ \mathrm{cm}^{2}$.

\section{3. Результаты и обсуждение}

Синтез $\mathrm{GaN}: \mathrm{Eu}^{3+}$ в порах МСМЧК осуществлялся в два этапа. На первом этапе в мезопоры вводился расплав кристаллогидрата $\mathrm{Ga}\left(\mathrm{NO}_{3}\right)_{3} \cdot 8 \mathrm{H}_{2} \mathrm{O}$, содержащего $0.22 \mathrm{мac} \% \mathrm{Eu}\left(\mathrm{NO}_{3}\right)_{3} \cdot 6 \mathrm{H}_{2} \mathrm{O}$. Расплав кристаллогидрата смачивает внутреннюю поверхность МСМЧК, состоящую из гидратированного $\mathrm{SiO}_{2}$. Смачивающая жидкость заполняет мезопоры под действием капиллярного (лапласова) давления $[19,20]$, которое, согласно формуле Лапласа, обратно пропорционально диаметру пор. Капиллярное давление в мезопорах в 30 раз превышает давление в пространстве между частицами [21], и, таким образом, благодаря капиллярным свойствам мезопор расплав преимушественно находится и разлагается внутри МСМЧК.

С целью разложения нитратов до оксидов проводился постепенный нагрев МСМЧК, заполненных расплавом, до температуры $800 \mathrm{~K}$. По данным термогравиметрического анализа [22], нитрат галлия последовательно разлагается по следующей схеме: $\quad \mathrm{Ga}\left(\mathrm{NO}_{3}\right)_{3} \cdot 8 \mathrm{H}_{2} \mathrm{O} \rightarrow \mathrm{Ga}(\mathrm{OH})_{2} \mathrm{NO}_{3} \rightarrow \mathrm{Ga}\left(\mathrm{NO}_{3}\right) \mathrm{O} \rightarrow$ $\mathrm{Ga}(\mathrm{OH})_{3} \rightarrow \mathrm{Ga}(\mathrm{OH}) \mathrm{O} \rightarrow \mathrm{Ga}_{2} \mathrm{O}_{3}$. $\mathrm{Ga}\left(\mathrm{NO}_{3}\right)_{3} \cdot 8 \mathrm{H}_{2} \mathrm{O}$ полностью переходит в $\mathrm{Ga}_{2} \mathrm{O}_{3}$ при температуре $\sim 750 \mathrm{~K}$. В свою очередь $\mathrm{Eu}\left(\mathrm{NO}_{3}\right)_{3} \cdot 6 \mathrm{H}_{2} \mathrm{O}$ полностью разлагается по аналогичной схеме [23] с образованием оксида европия при температурах, близких к $800 \mathrm{~K}$. Газообразными продуктами разложения кристаллогидратов нитратов галлия и европия являются $\mathrm{O}_{2}, \mathrm{H}_{2} \mathrm{O}$, $\mathrm{NO}_{2}$ и $\mathrm{N}_{2} \mathrm{O}_{5}$. В результате отжига при $800 \mathrm{~K}$ в течение 3 ч происходило формирование нанокомпозитных частиц $\mathrm{mSiO}_{2} / \mathrm{Ga}_{2} \mathrm{O}_{3}: \mathrm{Eu}^{3+}$. Степень заполнения мезопор $\mathrm{Ga}_{2} \mathrm{O}_{3}: \mathrm{Eu}^{3+}$, определенная по результатам измерения плотности частиц методом седиментации, составила 40 об \%.

Образование кристаллитов нитрида галлия внутри мезопор происходило в результате высокотемпературного отжига МСМЧК, содержащих $\mathrm{Ga}_{2} \mathrm{O}_{3}: \mathrm{Eu}^{3+}$, в атмосфере аммиака согласно следующему уравнению:

$$
\mathrm{Ga}_{2} \mathrm{O}_{3}(\mathrm{~s})+2 \mathrm{NH}_{3}(\mathrm{~g}) \rightleftarrows 2 \mathrm{GaN}(\mathrm{s})+3 \mathrm{H}_{2} \mathrm{O}(\mathrm{g}) .
$$

Известно, что галлий не образует силикатов [24]. Именно это обстоятельство обусловило принципиальную возможность реализации предложенной схемы синтеза. Если бы в системе $\mathrm{Ga}_{2} \mathrm{O}_{3}-\mathrm{SiO}_{2}$ существовали химические соединения, то наполнитель в процессе отжига прореагировал бы с материалом матрицы.

МСМЧК сохраняют температурную стойкость до $\sim 1000 \mathrm{~K}$, затем происходит размягчение и коалесценция частиц [17-20]. Согласно термодинамическим 
расчетам, энергия Гиббса реакции (1) при $1000 \mathrm{~K}$ положительная и составляет +60 кДж/моль. Следовательно, химическое равновесие смещено в сторону исходных реагентов, и $\mathrm{GaN}$ в данных условиях не образуется. Поэтому температуру процесса синтеза необходимо было увеличивать. Ранее синтез $\mathrm{GaN}$ в порах опала проводился при $1300 \mathrm{~K}$ [11-13], при этом опал сохранял температурную стойкость [25]. Расчетное значение энергии Гиббса реакции (1) при $1300 \mathrm{~K}$ составило +2 кДж/моль, константа равновесия $K_{p}$ близка к единице. Равновесное давление продукта реакции (1) водяного пара составило 900 Торр при давлении паров исходного реагента аммиака 1000 Торр. Таким образом, в данных условиях образование нитрида галлия термодинамически выгодно.

Поскольку плотность диффузионного потока молекул воды в порах МСМЧК пропорциональна градиенту ее концентрации, для увеличения скорости массопереноса необходимо было минимизировать концентрацию (давление паров) воды вблизи внешней поверхности частиц. Давление водяного пара в реакторе контролировалось и составляло менее 1 Торр в течение всей продолжительности синтеза, и, таким образом, концентрация молекул воды в порах и на внешней поверхности частиц отличалась на 3 порядка. Это обстоятельство позволило осуществить полное превращение $\mathrm{Ga}_{2} \mathrm{O}_{3}$ в $\mathrm{GaN}$ в порах МСМЧК, при этом, несмотря на столь длительный высокотемпературный отжиг $(1300 \mathrm{~K}, 20$ ч), частицы не коалесцировали (см. далее).

На рис. 1 представлено АСМ-изображение МСМЧК до и после гетерогенного синтеза $\mathrm{GaN}$ в мезопорах. Исходные МСМЧК имеют сферическую форму, шероховатость их поверхности $(\sim 10 \mathrm{HM})$ соответствует размерам образующих частицы кластеров гексагональноупакованных нанотрубок $\mathrm{SiO}_{2}[17,18]$. Форма нанокомпозитных частиц $\mathrm{mSiO}_{2} / \mathrm{GaN}: \mathrm{Eu}^{3+}$ также близка к сферической, однако шероховатость их поверхности больше, чем у исходных МСМЧК. Массивный $\mathrm{GaN}$ отсутствует на поверхности частиц и в пространстве между ними (рис. $1, b)$, что свидетельствует о том, что благодаря капиллярным свойствам $\mathrm{mSiO}_{2}$ расплав кристаллогидратов преимущественно находился и разлагался внутри МСМЧК.

Гетерогенный синтез GaN (реакция (1)) протекает внутри пор и не приводит к появлению массивного материала на поверхности частиц, поскольку мольный объем наполнителя в порах МСМЧК при синтезе $\mathrm{GaN}$ немного уменьшается. Мольные объемы $\left(V_{m}\right)$ реагентов и продуктов при нормальных условиях составляют: $V_{m}\left(\alpha-\mathrm{Ga}_{2} \mathrm{O}_{3}\right)=29.1 \mathrm{~cm}^{3} /$ моль, $V_{m}(\mathrm{GaN})=13.6 \mathrm{~cm}^{3} /$ моль. Изменение мольного объема в результате реакции $\Delta V_{m}(\mathrm{GaN})=2 \cdot V_{m}(\mathrm{GaN}) \cdot 100 \% / V_{m}\left(\alpha-\mathrm{Ga}_{2} \mathrm{O}_{3}\right)=93 \%$.

В расчете использованы значения плотностей веществ, взятые из работы [26].

По данным динамического светорассеяния (рис. 1,c), средний диаметр частиц $\mathrm{mSiO}_{2} / \mathrm{GaN}_{2} \mathrm{Eu}^{3+}$ составляет $190 \pm 25$ нм, что близко к величине диаметра исходных МСМЧК. Метод ДСР анализирует гидродинамические

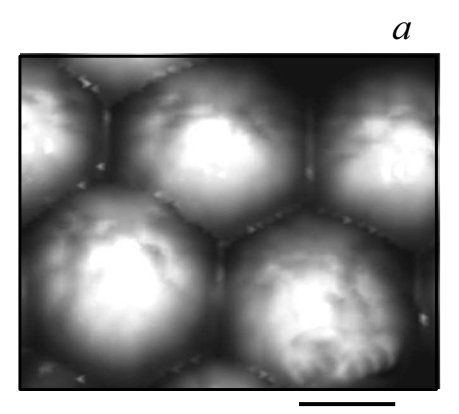

$100 \mathrm{~nm}$

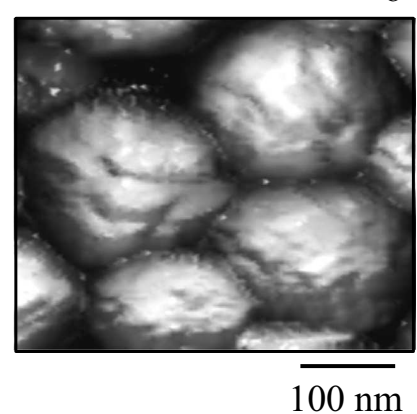

$c$

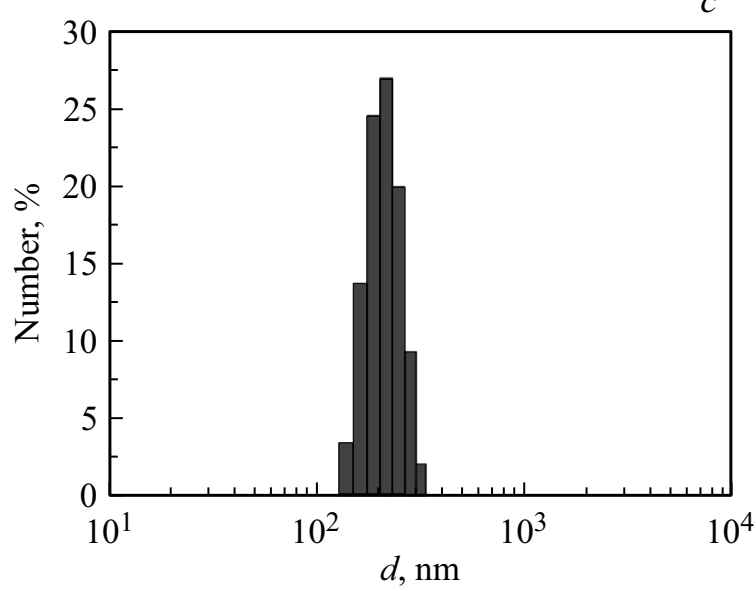

Рис. 1. $a-$ АСМ-изображение исходных МСМЧК; $b-\mathrm{ACM}$ изображение нанокомпозитных частиц $\mathrm{mSiO}_{2} / \mathrm{GaN}: \mathrm{Eu}^{3+}$; $c$ - распределение гидродинамических диаметров нанокомпозитных частиц, измеренное методом ДСР.

диаметры частиц в суспензии, а интенсивность динамического рассеяния света частицами пропорциональна их диаметру в шестой степени [27]. Отсутствие в анализируемой суспензии рассеивателей диаметром более $300 \mathrm{Hм}$ (рис. 1, c) свидетельствует о том, что при проведении гетерогенного синтеза частицы не коалесцировали (не сплавлялись) друг с другом, что, несомненно, происходило бы при отжиге незаполненных МСМЧК.

Отсутствие коалесценции нанокомпозитных частиц обусловлено химической инертностью $\mathrm{GaN}$ по отношению к $\mathrm{SiO}_{2}$ [24]. Ранее в порах синтетических опалов с помощью буферного слоя нитрида галлия, находящегося на поверхности пор матрицы, удалось предотвратить образование силиката цинка в нанокомпозите $\mathrm{SiO}_{2} / \mathrm{GaN} / \mathrm{ZnS}: \mathrm{Mn}^{2+}$ [28]. По-видимому, нитрид галлия, находящийся в приповерхностной области в нанокомпозитных частицах $\mathrm{mSiO}_{2} / \mathrm{GaN}: \mathrm{Eu}^{3+}$, также выступает в качестве буферного слоя и препятствует коалесценции частиц. Однако при температуpe $1300 \mathrm{~K}$ происходило перераспределение материала внутри нанокомпозитных частиц, увеличивалась шероховатость частиц (рис. $1, b$ ) и исчезала мезопористая структура. В частности, значение удельной поверхности 


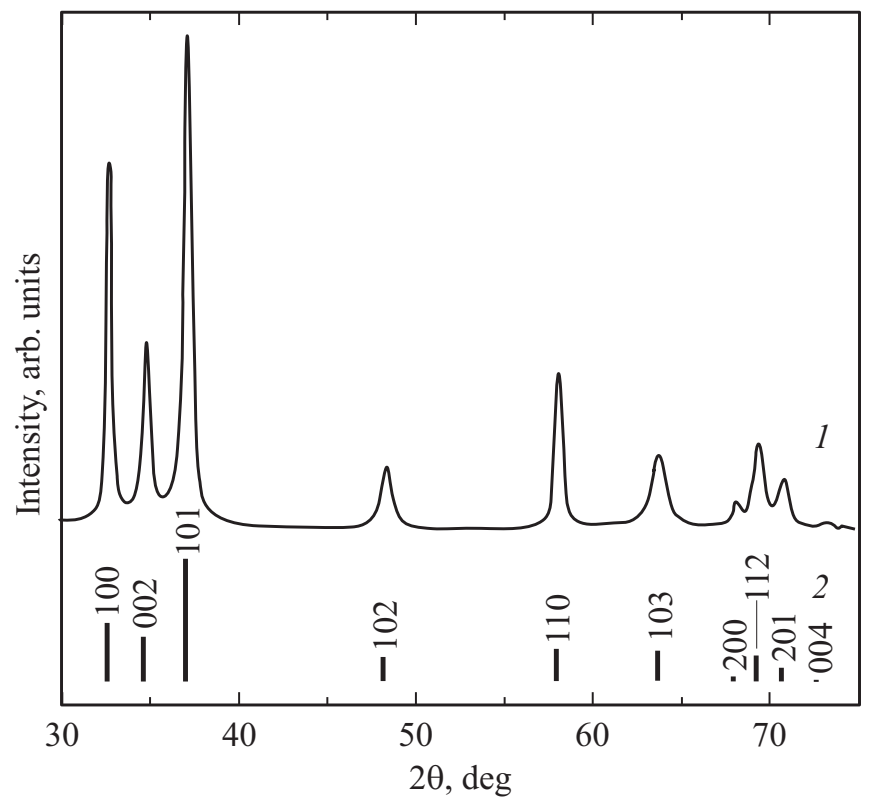

Рис. 2. Дифрактограммы: $1-\mathrm{mSiO}_{2} / \mathrm{GaN}_{2} \mathrm{Eu}^{3+}, 2-\mathrm{GaN}$ (JCPDS 50-0792).

$\mathrm{mSiO}_{2} / \mathrm{GaN}: \mathrm{Eu}^{3+}$, по данным азотной адсорбционной порометрии, составило менее $15 \mathrm{~m}^{2} /$ г.

Наличие в порах нитрида галлия подтверждено методами порошковой рентгеновской дифрактометрии и рамановской спектроскопии. На дифракционных кривых нанокомпозитных частиц наблюдается набор рефлексов (рис. 2, кривая 1), соответствующих гексагональному GaN (JCPDS 50-0792) (рис. 2, кривая 2). Примесные фазы, например оксиды галлия, в составе композитных частиц не обнаружены, а следовательно, процесс формирования нанокристаллитов $\mathrm{GaN}: \mathrm{Eu}^{3+}$ из $\mathrm{Ga}_{2} \mathrm{O}_{3}: \mathrm{Eu}^{3+}$ в порах проходит полностью. Нитрид галлия в составе нанокомпозитных частиц хорошо кристаллизован. Рассчитанный методом Ритвельда средний размер области когерентного рассеяния составил 29 нм, что значительно больше диаметра мезопор. По-видимому, при температуре синтеза $1300 \mathrm{~K}$ вследствие диффузии атомов $\mathrm{Ga}$ и $\mathrm{N}$ в аморфном $\mathrm{SiO}_{2}$ [29], происходит перекристаллизация (увеличение размеров кристаллитов) нитрида галлия, поскольку это более термодинамически выгодно. Кроме того, форма кристаллитов гексагонального $\mathrm{GaN}$ может быть анизотропной, что также приводит к увеличению размеров области когерентного рассеяния.

На рис. 3 представлен рамановский спектр нанокомпозитных частиц $\mathrm{SiO}_{2} / \mathrm{GaN}: \mathrm{Eu}^{3+}$ в области частот $450-850 \mathrm{~cm}^{-1}$. В спектре наблюдаются две широкие полосы. Низкочастотная полоса $\left(530-570 \mathrm{~cm}^{-1}\right)$ связана с областью поперечных фононов симметрии $A_{1}(\mathrm{TO})$ и $E_{1}(\mathrm{TO})$ и неполярного фонона симметрии $E_{2}$ (high) гексагонального $\mathrm{GaN}$. Высокочастотная полоса с максимумом $\sim 733 \mathrm{~cm}^{-1}$ возникает из продольных составляющих полярных фононов симметрии $A_{1}(\mathrm{LO})$ и $E_{1}(\mathrm{LO})$. На рис. 3 стрелками показано положение раман-активных фононных мод $A_{1}(\mathrm{TO}), E_{1}(\mathrm{TO}), E_{2}$ (high), $A_{1}(\mathrm{LO})$ и $E_{1}(\mathrm{LO})$ гексагонального $\mathrm{GaN}$ [30]. Такой вид спектра является характерным для кристаллитов $\mathrm{GaN}$ ограниченного размера [13]. Следует отметить, что в форму рамановского спектра вносит вклад спектр люминесценции ионов $\mathrm{Eu}^{3+}$, а именно наблюдается наклон кривой относительно оси ординат. Раман-активных фононных мод, характерных для примесных фаз, например $\mathrm{Ga}_{2} \mathrm{O}_{3}$ [31], не выявлено, что согласуется с данными рентгеновской дифракции.

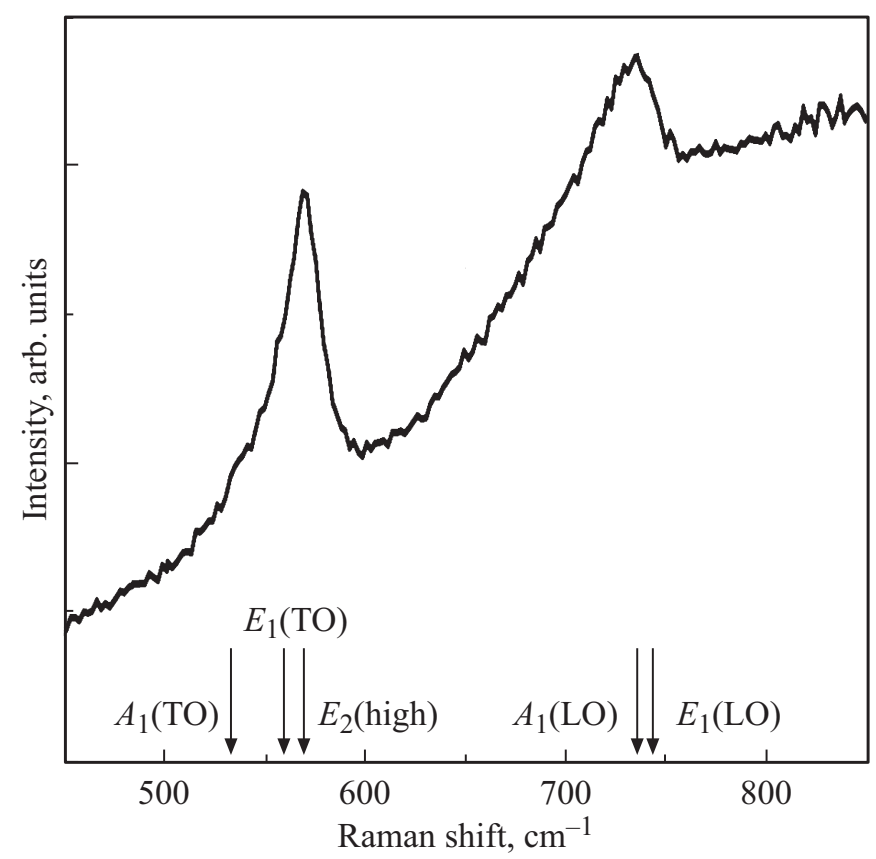

Рис. 3. Рамановский спектр нанокомпозитных частиц $\mathrm{mSiO}_{2} / \mathrm{GaN}: \mathrm{Eu}^{3+}$. Обозначены раман-активные фононные моды.

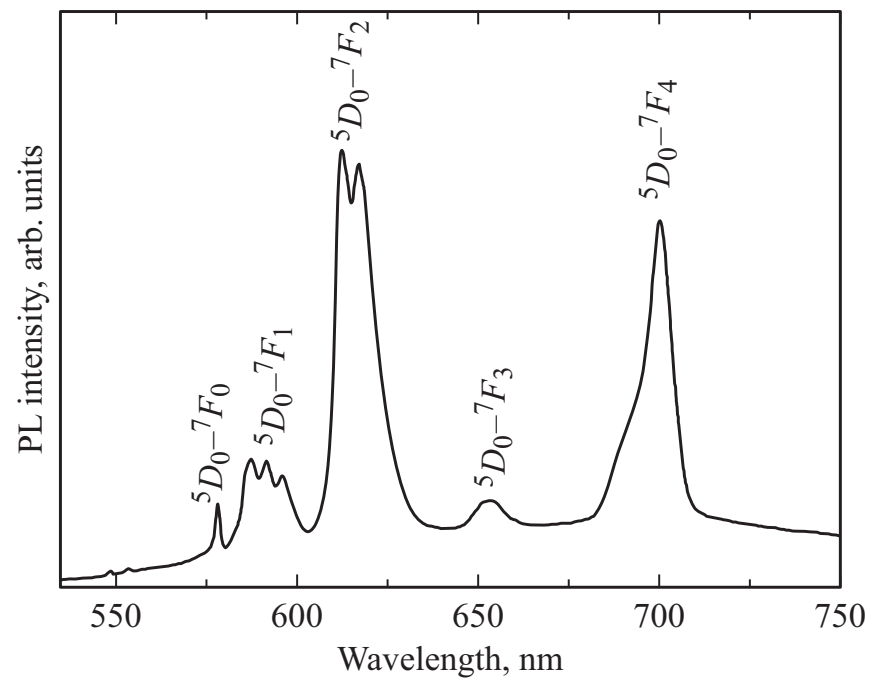

Рис. 4. Спектр фотолюминесценции нанокомпозитных частиц $\mathrm{mSiO}_{2} / \mathrm{GaN}: \mathrm{Eu}^{3+}$. 
На рис. 4 представлен спектр ФЛ нанокомпозитных частиц $\mathrm{mSiO}_{2} / \mathrm{GaN}: \mathrm{Eu}^{3+}$ при возбуждении $\mathrm{Nd}$ : YAG-лазером с длиной волны 532 нм. В спектре ФЛ наблюдается группа линий, характерных для внутрицентровых переходов в ионах $\mathrm{Eu}^{3+}:{ }^{5} \mathrm{D}_{0} \rightarrow{ }^{7} \mathrm{~F}_{J}(J=0$, $1,2,3,4)[32]$. Спектры ФЛ частиц $\mathrm{mSiO}_{2} / \mathrm{GaN}: \mathrm{Eu}^{3+}$ измерялись как непосредственно после гетерогенного синтеза, так и после нахождения частиц в водной суспензии в течение месяца. Форма спектров и интенсивность линий не изменялись, что свидетельствует о том, что полученный люминесцентный материал не подвержен деградации в водной среде.

\section{4. Заключение}

В настоящей работе синтезированы нанокристаллиты $\mathrm{GaN}: \mathrm{Eu}^{3+}$ в порах монодисперсных сферических частиц мезопористого кремнезема. Предложен способ заполнения пор МСМЧК расплавом кристаллогидратов нитратов галлия и европия, с последующим термическим разложением кристаллогидратов до оксидов. Степень заполнения мезопор после однократной пропитки расплавом и его терморазложения составила 40\% от общего объема пор в частицах. В термодинамически равновесных условиях посредством отжига при температуре $1300 \mathrm{~K}$ в атмосфере аммиака из оксида галлия был получен нитрид галлия, легированный ионами $\mathrm{Eu}^{3+}$. Предложенный метод гетерогенного синтеза накомпозитных частиц состава $\mathrm{mSiO}_{2} / \mathrm{GaN}: \mathrm{Eu}^{3+}$ является простым, высокотехнологичным и позволяет проводить гетерогенные химические реакции в наноразмерных порах.

Методами АСМ и ДСР показано, что частицы после заполнения имеют сферическую форму и являются монодисперсными. Отсутствие коалесценции частиц обусловлено наличием в их составе соединений галлия, выступающих в качестве буферного слоя.

Методами рентгеновской дифракции и рамановской спектроскопии показано, что оксид галлия в мезопорах полностью переходит в гексагональный $\mathrm{GaN}$. Исследования фотолюминесценции нанокомпозитных частиц $\mathrm{mSiO}_{2} / \mathrm{GaN}_{2} \mathrm{Eu}^{3+}$ показали наличие в спектрах ФЛ группы линий, характерных для внутрицентровых переходов в ионах $\mathrm{Eu}^{3+}$.

Исследования частично выполнены с использованием оборудования ЦКП „Материаловедение и диагностика в передовых технологиях“.

Работа выполнена при финансовой поддержке РФФИ (№ 15-52-12011) и DFG в рамках ICRC TRR 160.

\section{Список литературы}

[1] Y. Waseda, A. Muramatsu. Morphology control of matherials and nanoparticles (Springer, 2004) XV, v. 64. 262 p.

[2] S.K. Kumar, R. Krishnamoorti. Annual Rev. Chem. Biomol. Eng 1, 37 (2010).
[3] P.H.C. Camargo, K.G. Satyanarayana, F. Wypych. Mater. Res., 12 (1), 1 (2009).

[4] Q. Wang, D.F. Shantz. J. Solid State Chem., 181, 1659 (2008).

[5] A. Stein, B.E. Wilson, S.G. Rudisill. Chem. Soc. Rev., 42, 2763 (2013).

[6] S Salimian, A. Zadhoush, A. Mohammadi. J. Reinforced Plastics Composites, 0, 1 (2018).

[7] X. Pan, X. An, Z. Zhang, J. Zhou, E. Xie. J. Alloys Comp., 519, 6 (2012).

[8] S. Shirakata, R. Takashi, K. Sasaki. Appl. Phys. Lett., 85, 2247 (2004).

[9] R. Bilyy, A. Podhorodecki, M. Nyk, R. Stoika, A. Zaichenko, G. Zatryb, J. Misiewicz, W. Strek. Physica E, 40, 2096 (2008).

[10] R. Bilyy, A. Tomyn, Y. Kit, A. Podhorodecki, J. Misiewicz, M. Nyk, W. Strek, R. Stoika. Mat. Werkstofftech., 40, 234 (2009).

[11] V.Yu. Davydov, V.G. Golubev, N.F. Kartenko, D.A. Kurdyukov, A.B. Pevtsov, N.V. Sharenkova, P. Brogueira, R. Schwarz. Nanotechnology, 11, 291 (2000).

[12] В.Г. Голубев, Д.А. Курдюков, А.В. Медведев, А.Б. Певцов, Л.М. Сорокин, Д. Хатчисон. ФТП, 35, 1376 (2001).

[13] V.Yu. Davydov, R.E. Dunin-Borkovski, V.G. Golubev, J.L. Hutchison, N.F. Kartenko, D.A. Kurdyukov, A.B. Pevtsov, N.V. Sharenkova, J. Sloan, L.M. Sorokin. Semicond. Sci. Technol., 16, L5 (2001).

[14] F.A.L. Dullien. Porous Media Fluid Transport and Pore Structure. 2nd edn (Academic Press Inc., 1992).

[15] E.R. Gilliland, R.F. Baddour, J.L. Russell. AIChE Journal, 4, 90 (1958).

[16] Д.А. Курдюков. Нанотехника, 4, 18 (2007).

[17] Е.Ю. Трофимова, Д.А. Курдюков, Ю.А. Кукушкина, М.А. Яговкина, В.Г. Голубев. Физика и химия стекла, $\mathbf{3 7}$, 38 (2011).

[18] E.Yu. Trofimova, D.A. Kurdyukov, S.A. Yakovlev, D.A. Kirilenko, Yu.A. Kukushkina, A.V. Nashchekin, A.A. Sitnikova, M.A. Yagovkina, V.G. Golubev. Nanotechnology, 24, 155601 (2013).

[19] D.A. Eurov, D.A. Kurdyukov, D.A. Kirilenko, J.A. Kukushkina, A.V. Nashchekin, A.N. Smirnov, V.G. Golubev. J. Nanopart. Res., 17, 82 (2015).

[20] Е.Ю. Стовпяга, Д.А. Еуров, Д.А. Курдюков, А.Н. Смирнов, М.А. Яговкина, В.Ю. Григорьев, В.В. Романов, D.R. Yakovlev, В.Г. Голубев. ФТТ, 59, 1598 (2017).

[21] Д.А. Курдюков, Д.А. Еуров, Е.Ю. Стовпяга, С.А. Яковлев, Д.А. Кириленко, В.Г. Голубев. ФТТ, 56, 995 (2014).

[22] V. Berbenni, C. Milanese, G. Bruni, A. Marini. J. Therm. Anal. Calorim., 82, 401 (2005).

[23] P. Melnikov, I.V. Arkhangelsky, V.A. Nascimento, L.C.S. de Oliveira, A.F. Silva, L.Z. Zanoni. J. Therm. Anal. Calorim., 128, 1353 (2017).

[24] П.И. Федоров, М.В. Мохосоев, Ф.П. Алексеев. Химия галлия, индия и таллия (Новосибирск, Наука, 1977).

[25] G.M. Gajiev, D.A. Kurdyukov, V.V. Travnikov. Nanotechnology, 17, 5349 (2006).

[26] Milnes A.G. Deep Impurities in Semiconductors (N. Y., John Wiley and Sons, 1973).

[27] А.Е. Алексенский, А.В. Швидченко, Е.Д. Эйдельман. Письма ЖТФ, 38 (23), 1 (2012).

[28] S.F. Kaplan, N.F. Kartenko, D.A. Kurdyukov, A.V. Medvedev, V.G. Golubev. Appl. Phys. Lett., 86, 071108 (2005).

[29] J. Kioseoglou, M. Katsikini, K. Termentzidis, I. Karakostas, E.C. Paloura. J. Appl. Phys., 121, 054301 (2017). 
[30] V.Yu. Davydov, Yu.E. Kitaev, I.N. Goncharuk, A.N. Smirnov, J. Graul, O. Semchinova, D. Uffmann, M.B. Smirnov, A.P. Mirgorodsky, R.A. Evarestov. Phys. Rev. B, 58, 12899 (1998).

[31] Y.H. Gao, Y. Bando, T. Sato, Y.F. Zhang, X.Q. Gao. Appl. Phys. Lett., 81, 2267 (2002).

[32] K. Binnemans. Coord. Chem. Rev., 295, 1 (2005).

Редактор А.Н. Смирнов

\section{Template synthesis of monodisperse spherical nanocomposite $\mathrm{SiO}_{2} / \mathrm{GaN}: \mathrm{Eu}^{3+}$ particles}

E.Yu. Stovpiaga ${ }^{1}$, D.A. Eurov' ${ }^{1}$, D.A. Kurdyukov' ${ }^{1}$, A.N. Smirnov ${ }^{1}$, M.A. Yagovkina ${ }^{1}$, D.R. Yakovlev ${ }^{2}$, V.G. Golubev ${ }^{1}$

${ }^{1}$ loffe Institute, 194021 St. Petersburg, Russia

${ }^{2}$ Experimentelle Physik 2,

Technische Universität Dortmund, D-44227 Dortmund, Germany

Abstract A nanocomposite has been synthesized as monodisperse spherical mesoporous silica particles $\left(\mathrm{mSiO}_{2}\right)$, filled with $\mathrm{GaN}: \mathrm{Eu}^{3+}$ by template method. The method is based on a capillary impregnation of the pores of $\mathrm{mSiO}_{2}$ particles with the melt of gallium and europium $(0.22 \%$ wt. $)$ nitrates hydrates with subsequent thermal decomposition and ammonia treatment. It is shown that nanocomposite particles contain hexagonal $\mathrm{GaN}: \mathrm{Eu}^{3+}$, are of spherical shape, monodisperse and do not coalesce. The photoluminescence spectra of $\mathrm{mSiO}_{2} / \mathrm{GaN}_{\mathrm{E}} \mathrm{Eu}^{3+}$ particles show a group of lines associated with intracenter transitions in $\mathrm{Eu}^{3+}$. 